\title{
THE IMPLEMENTATION OF AN ENVIRONMENTAL MANAGEMENT SYSTEM AND ITS CONTRIBUTIONS TO TODAY'S ORGANIZATIONS
}

\author{
Vanda Feleol da Mota ${ }^{1}$
}

${ }^{1}$ Faculdade Venda Nova do Imigrante (FAVENI). Av. Ângelo Altoé, 888, 29375-000, Venda Nova do Imigrante - ES, Brasil.

Email: tutoria17@ posgraduacaofaveni.com.br

Received: May 24th 2019

Accepted: June 25th 2019

Published: September $30^{\text {th }}$, 2019

Copyright (C2016 by authors and Institute of Technology Galileo of Amazon (ITEGAM). This work is licensed under the Creative Commons Attribution International License (CC BY 4.0). https://creativecommons.org/lice nses/by/4.0/

\begin{abstract}
Currently the concern with the environment is essential for companies vying for a share in the international market. Concerns that a few decades ago were not as important for choosing products of certain segments, are now both consumers and producers rethink some concepts throughout the development process. Upon the foregoing, it has been the theme in this work the implementation of an enterprise system environment, limiting the observation of the importance of an EMS - Environmental Management System and contributions to organizations today. The reason is because the theme of environmental management concern itself not only with sustainability and preservation of the environment, but also with the quality, social responsibility, and changing paradigms, especially in the financial opportunities that companies tend to win when inserted in environmental programs. The objectives of this work include in general and specific: The overall objective is to describe the importance of Environmental Management and its benefits to the EMS - Environmental Management System and organizations. The specific objectives are to analyze the Environmental Management and its favorable aspects organizations, check the Environmental Management System and its organizational aspects and to identify the benefits of implementing an EMS organization today. For a company really is with the Environmental Management implemented, it must go through long processes of evaluations, changes, audits, ongoing procedures to complete the certification process ISO 14000 International call. Thus, the methodology of this study consists of a bibliographic research, descriptive, without investigative character, just observational. It is expected, however, contribute to future research in addition to leveraging bibliography about theme presented.
\end{abstract}

Keywords: Environmental Management, Environmental Management System, Social Responsibility.

\section{RESUMO}

Atualmente a preocupação com o meio ambiente é fundamental para as empresas que disputam uma fatia no mercado internacional. Preocupações que há algumas décadas não eram tão importantes para a escolha de produtos de certos segmentos, fazem hoje tanto o consumidor quanto o produtor repensarem alguns conceitos em todo o processo de desenvolvimento. Mediante o exposto, tem-se como tema neste trabalho a implantação de um sistema ambiental empresarial, delimitando-se na observação da importância de um SGA - Sistema de Gestão Ambiental e suas contribuições para as organizações na atualidade. A justificativa da temática é pelo fato da gestão ambiental preocupar-se não apenas com a sustentabilidade e preservação do meio ambiente, mas também com a qualidade, responsabilidade social, mudança de paradigmas e, sobretudo, nas oportunidades financeiras que as empresas tendem a conquistar quando inseridas nos programas ambientais. Os objetivos deste trabalho compreendem-se em geral e específicos: O objetivo geral consiste em descrever a importância da Gestão Ambiental e seus benefícios ao SGA - Sistema de Gestão Ambiental e às organizações. Os objetivos específicos consistem em analisar a Gestão Ambiental e seus aspectos favoráveis às organizações; verificar o Sistema de Gestão Ambiental e seus aspectos organizacionais; e identificar os benefícios da implantação de um SGA organizacional na atualidade. Para que uma empresa realmente esteja com a Gestão Ambiental implantada, ela deverá passar por longos processos de avaliações, mudanças, auditorias, procedimentos contínuos para que conclua o processo de certificação Internacional chamada ISO 14000. Assim, a metodologia deste trabalho consiste em uma pesquisa bibliográfica, descritiva, sem caráter investigativo, apenas o observacional. Espera-se, contudo, contribuir para pesquisas futuras além de alavancar a bibliografia acerca da temática apresentada.

Palavras-chave: Gestão Ambiental, Sistema de Gestão ambiental, Responsabilidade Social. 


\section{INTRODUÇÃO}

A evolução tecnológica e a ascensão populacional dos grandes centros urbanos, o desmatamento desenfreado e os poluentes industriais despejados no meio ambiente, até pouco tempo não chamavam a atenção da sociedade. Devido à escassez de recursos o sistema jurídico e legisladores de muitas nações observaram a necessidade de leis reguladoras das atividades que envolvessem risco ao meio ambiente, criando-se então o conceito de gestão ambiental, o qual constitui matéria exigida a toda pessoa física ou jurídica que execute atividades causadoras de danos ao ecossistema.

A gestão ambiental prevê a boa administração do patrimônio ecológico. A adaptação da comunidade global às normas legais ambientais foi visivelmente percebida nas últimas décadas através das políticas de educação ambiental ou por sanções impostas por Lei.

Justifica-se esse trabalho, pelo fato da gestão ambiental preocupar-se não apenas com a sustentabilidade e preservação do meio ambiente, mas também com a qualidade, responsabilidade social, mudança de paradigmas e, sobretudo, nas oportunidades financeiras que as empresas tendem a conquistar quando inseridas nos programas ambientais.

Os objetivos compreendem-se em geral e específicos: $\mathrm{O}$ objetivo geral consiste em descrever a importância da Gestão Ambiental e seus benefícios ao SGA - Sistema de Gestão Ambiental para as organizações. Os objetivos específicos visam analisar a Gestão Ambiental e seus aspectos favoráveis às organizações; verificar o Sistema de Gestão Ambiental e seus aspectos organizacionais; e identificar os benefícios da implantação de um SGA organizacional na atualidade.

Para que uma empresa realmente obtenha a certificação da Gestão Ambiental, é necessário enfrentar processos de avaliações, mudanças, auditorias, procedimentos contínuos para que conclua o processo de certificação Internacional chamada ISO 14000.

Baseado no exposto, a metodologia deste trabalho consiste em uma pesquisa bibliográfica, descritiva, sem caráter investigativo, apenas o observacional. Espera-se, contudo, contribuir para pesquisas futuras além de alavancar a bibliografia acerca da temática apresentada.

Do ponto de vista empresarial, a primeira dúvida em relação a questão ambiental, diz respeito ao aspecto econômico. A ideia que prevalece é de que qualquer providência que venha a ser tomada em relação à variável ambiental traz consigo o aumento de despesas e acréscimo dos custos do processo produtivo

\section{REVISÃO BIBLIOGRÁFICA}

\section{II.1 A GESTÃO AMBIENTAL}

Sobre a questão ambiental surge a interrogativa sobre a concessão da responsabilidade pelos danos causados ao meio ambiente, e pela gestão ambiental. Conhecer e apontar os devidos responsáveis por determinadas áreas verdes e biomas é apenas um primeiro passo para a solução da crise ambiental, porém é um passo importante e ainda não plenamente executado. Esta tarefa torna-se extremamente trabalhosa nas comunidades atuais, onde as pressões mercadológicas e políticas dão voz às decisões relacionadas ao tema [1].

Para aplicar uma gestão ambiental de sucesso é imprescindível entender o que é o desenvolvimento sustentável. A sustentabilidade prioriza o uso consciente, uma vez conhecida a capacidade de renovação de si própria da natureza, porém esta é limitada, cabendo ao homem conhecer seus limites na exploração dos recursos naturais [2]. Dentre outras características, o desenvolvimento sustentável tem enfoque na cooperação e participação, a ética integrada ao cotidiano e a transdisciplinaridade.

A gestão ambiental tem atualmente um papel fundamental para o grupo administrativo de qualquer empresa [3]. A conscientização ecológica veio para alertar não apenas as sociedades, mas também os governantes a respeito da causa ambiental, e fez surgir o dever de responsabilidade social e ecológica praticada por empresários e avaliada pelas comunidades [4].

Sob esta perspectiva Kraemerapud [5] esclarece a gestão ambiental da seguinte maneira:

Objeto de manter o meio ambiente saudável (à medida do possível), para atender as necessidades humanas atuais, sem comprometer $\mathrm{o}$ atendimento das necessidades das gerações futuras.

Meio de atuar sobre as modificações causadas no meio ambiente pelo uso e/ou descarte dos bens e detritos gerados pelas atividades humanas, a partir de um plano de ações viáveis técnica e economicamente, com prioridades perfeitamente definidas.

Instrumentos de monitoramentos, controles, taxações, imposições, subsídios, divulgação, obras e ações mitigadoras, além de treinamento e conscientização.

Base de atuação de diagnósticos (cenários) ambientais da área de atuação, a partir de estudos e pesquisas dirigidos em busca de soluções para os problemas que forem detectados.

Nesse sentido, [6] afirma que para ser efetivo e eficaz, o Sistema de Gestão Ambiental (SGA) implantado em uma instituição necessita de requisitos essenciais, tais como:

Política ambiental: comprometimento oficial e documentado da empresa para com o meio ambiente.

Planejamento: estabelece os processos da linha de produção e seus efeitos na natureza, delimitando um programa ambiental para reverter estes efeitos e um responsável por executálos e/ou monitorá-los em cada área. Os índices obtidos no estudo do planejamento devem constar na política ambiental.

Implementação: esta etapa especifica as competências da administração com relação à execução do SGA, dentre as quais a divulgação dos processos e resultados interna e externamente à instituição, a capacitação e conscientização da equipe de colaboradores quanto à relevância do sistema, a configuração da documentação legal exigida, providenciar planos destinados a suprir demandas em situações de emergência, etc.

Verificações e ações corretivas: objetiva a manutenção dos processos do SGA, bem como sua documentação e divulgação acessível a todos. Também requisita auditorias periódicas do sistema a fim de sustentar seu correto funcionamento.

Revisão pela direção: decreta que o alto escalão administrativo deve frequentemente avaliar o andamento, a adequabilidade e o sucesso do sistema, criando disponibilidade para eventuais alterações nos procedimentos, planos de emergência, ações corretivas, bem como na própria política ambiental. Todas estas decisões devem ser devidamente documentadas.

Um SGA aplicado de forma disciplinada e consciente resulta em uma série de vantagens, como já mencionado, dentre as quais cabe elucidar a conceituação o termo "passivo ambiental". Refere-se às despesas monetárias investidas por uma instituição, dentro do sistema de gestão, para a recuperação de áreas naturais bem como para a tomada de atitudes preventivas, remediativas e pró-ativas dentro do planejamento ambiental [7]. 


\section{1.1 SISTEMA DE GESTÃO AMBIENTAL}

O cenário de desenvolvimento até então construído pelas indústrias, as quais podem ser consideradas a engrenagem econômica de uma nação, revelou também que certos setores industriais são mais impactantes ao meio ambiente do que outros. Conforme Gusmão e Martini Júnior salientam:

Alguns setores industriais se caracterizam por um elevado potencial de degradação ambiental quando comparado com outras atividades industriais, como o setor de bens intermediários (minerais não-metálicos, metalurgia, papel e celulose, petróleo e química), seja pelo potencial de alteração da qualidade do ar e corpos hídricos, seja como consumidores diretos de recursos naturais e energia. Este potencial poluidor está relacionado ao nível das tecnologias adotadas e à intensidade das restrições legais [8].

Como exemplos de alguns setores industriais que degradaram o ambiente ao longo dos anos, são os da indústria química e de petróleo, quando ocorreram uma série de acidentes entre os anos de 1970 e 1980 ao redor do mundo.

As normas ISO 14.001 e ISO 14.004 têm por objetivo prover às organizações os elementos de um Sistema de Gestão Ambiental eficaz, passível de integração com os demais objetivos da organização. Sua concepção foi idealizada de forma a aplicar-se a todos os tipos e partes de organizações independentemente de suas condições geográficas, culturais e sociais.

A Norma ISO 14.004 especifica os princípios e os elementos integrantes de um Sistema de Gestão Ambiental (SGA).

Princípio 1 - Comprometimento e Política: "É recomendado que uma organização defina sua política ambiental e assegure o comprometimento com o seu SGA".

- Comprometimento e liderança da Alta Administração

- Avaliação ambiental inicial

- Estabelecimento da política ambiental

Princípio 2 - Planejamento: "É recomendado que uma organização formule um plano para cumprir sua política ambiental."

- Identificação de aspectos ambientais e avaliação dos impactos ambientais associados

- Requisitos legais e outros requisitos

- Critérios internos de desempenho

- Objetivos e metas ambientais

- Programa de gestão ambiental

Princípio 3 - Implementação: "Para uma efetiva implementação, é recomendado que uma organização desenvolva a capacitação e os mecanismos de apoio necessários para atender sua política, seus objetivos e metas ambientais."

- Assegurando a capacitação

- Recursos humanos, físicos e financeiros

- Harmonização e integração do SGA

- Responsabilidade técnica e pessoal

- Conscientização ambiental e motivação

- Conhecimentos, habilidades e atitudes

- Ações de apoio

- Comunicação e relato

- Documentação do SGA

- Controle operacional

- Preparação e atendimento a emergências

Princípios 4 - Medição e Avaliação: "É recomendado que uma organização meça, monitore e avalie seu empenho ambiental.

- Medição e monitoramento

- Ações corretiva e preventiva

- Registros do SGA e gestão de informação
Princípio 5 - Análise Crítica e Melhoria: "É recomendado que uma organização analise criticamente e aperfeiçoe constantemente seu sistema de gestão ambiental com o objetivo de melhorar seu desempenho ambiental global."

- Análise crítica do SGA

- Melhoria contínua

A cada dia que passa, a sociedade preocupa-se cada vez mais com a degradação do meio ambiente, fato este que obriga as empresas atentarem cada vez mais em relação a preservação da natureza.

A questão ambiental passa a fazer parte de um quadro de ameaças e oportunidades cujas consequências podem significar posições privilegiadas perante a concorrência, como também comprometer a empresa fazendo ela chegar até a sair do mercado.

$\mathrm{O}$ autor fornece ótimas informações para as organizações que, preocupadas com o problema, desejam ampliar conhecimentos para uma gestão ambiental dentro de sua empresa.

Certamente questões ecológicas, sustentáveis e ambientais nem sempre assumiram o ranking de metas das empresas e estas, por sua vez, tão pouco demonstraram algum indício de gestão ambiental em suas rotinas. Porém esse cenário tem sofrido positivas transformações, uma vez que o conceito de gestão ambiental se encaixa aos processos das organizações, independentemente de seu porte e na maioria dos setores [2].

Diante desta definição o entendimento pelo termo se torna mais objetivo, pois relata noções de conhecimentos técnicos e administrativos baseados nos quesitos ambientais, ou seja, a gestão ambiental é diretamente ligada à administração dos negócios ou ramo da atividade.

\section{1.2 RESPONSABILIDADE SOCIAL E O MEIO AMBIENTE}

Com a ameaça da escassez dos recursos naturais, vêm-se buscando alternativas para que o desenvolvimento socioeconômico seja sustentável.

A introdução do capital natural na análise econômica fazse necessário já que os custos da degradação ambiental e do consumo de recursos naturais não têm sido adicionados aos processos produtivos, avaliando-se os fluxos de estoques naturais e contribuindo para a definição de uma escala sustentável da economia. A valoração ambiental é essencial, caso se pretenda que a degradação da grande maioria dos recursos naturais seja interrompida antes que ultrapasse o limite da irreversibilidade [9].

A pressão crescente, em nível mundial, existe sobre as organizações industriais para que adotem medidas de proteção ao meio ambiente, faz com que as empresas, dependendo do contexto em que atuam, reformulem suas estratégias competitivas incluindo a variável ambiental [10]. Quando estas organizações industriais abrangem uma grande área produtiva do País, o problema do gerenciamento ambiental se torna essencial, como é o caso do complexo agroindustrial canavieiro, pois a cana para a indústria é a mais importante lavoura do País, tanto quando se visualiza sua contribuição para o valor da produção, quanto à sua geração de emprego.

A idéia de se evidenciarem os valores monetários dos recursos naturais se justifica pelo fato de que estes valores monetários podem ser utilizados como padrão de medida. $\mathrm{O}$ valor econômico do meio ambiente tem sido objeto de intensa discussão [11].

O valor econômico total (VET) de um recurso consiste em seu valor de uso (VU) em seu valor de não-uso (VNU). O valor de uso pode ainda ser subdividido em valor de uso direto (VUD), valor de uso indireto (VUI) e valor de opção (VO) (valor de uso 
potencial). O valor de existência (VE) é uma das principais categorias do valor de não-uso. Pode ser escrito:

$$
\begin{aligned}
& \mathrm{VET}=\mathrm{VU}+\mathrm{VNU} \text { ou } \\
& \mathrm{VET}=(\mathrm{VUD}+\mathrm{VUI}+\mathrm{VO})+\mathrm{VNU}
\end{aligned}
$$

Desta forma, o valor de uso direto é determinado pela contribuição direta que um recurso natural faz para o processo de produção e consumo. $\mathrm{O}$ valor de uso indireto inclui os benefícios derivados basicamente dos serviços que o ambiente proporciona para suportar o processo de produção e consumo. $\mathrm{O}$ valor de opção é a quantia que os consumidores estão dispostos a pagar por um recurso não utilizado na produção, simplesmente para evitar o risco de não tê-lo no futuro [9].

O valor de uso é atribuído pelas pessoas que realmente usam ou usufruem do meio ambiente em risco, por meio de dados estatísticos. Os valores de uso direto e indireto estão associados com as possibilidades presentes do uso dos recursos.

Aquelas pessoas, porém que não usufruem o meio ambiente podem também valorá-lo em relação a usos futuros, seja para elas mesmas ou para gerações futuras. Esse valor é referido como valor de opção, ou seja, opção para uso futuro ao invés do uso presente conforme compreendido no valor de uso. $\mathrm{O}$ valor de existência é mais difícil de conceituar, já que representa um valor atribuído à existência do meio ambiente independentemente do uso atual e futuro [9].

Os valores de existência, de acordo com [12], são aqueles expressos pelos indivíduos, de tal forma que não são relacionados ao uso presente ou futuro dos recursos ambientais pela geração presente e nem pelo possível uso que se possa atribuir em nome da geração futura. $\mathrm{O}$ conceito de valor de existência aproxima economistas e ecólogos, o que deverá proporcionar melhor e mais profundo entendimento da questão ambiental, na tentativa de captar todos os valores que um recurso ambiental possa conter. As pessoas atribuem esses valores de acordo com a avaliação que fazem da singularidade e da irreversibilidade da destruição do meio ambiente, associadas à incerteza da extensão dos seus efeitos negativos.

As categorias de valores de não uso são o valor de existência (VE) e o valor e legado (VL). Pode-se escrever: VET = $[\mathrm{VUD}+\mathrm{VUI}+\mathrm{VO}]+[\mathrm{VE}+\mathrm{VL}]$.

$\mathrm{O}$ valor de opção é baseado em quanto os indivíduos estão dispostos a pagar pela opção de preservar um bem para uso pessoal direto ou indireto no futuro.

Os métodos de valoração, segundo [12], de modo geral, não possuem uma classificação rígida, podendo-se utilizar diversos enfoques na aplicação dos métodos, dependendo dos propósitos.

Do ponto de vista didático, no entanto, torna-se interessante uma abordagem maleável destes métodos que permita as alterações que se fizerem necessárias durante suas aplicações. Assim, duas categorias de métodos de valoração ambiental podem ser distinguidas da seguinte forma: métodos diretos e métodos indiretos [3].

Os métodos diretos podem estar diretamente relacionados aos preços de mercado ou produtividade, e são baseados nas relações físicas que descrevem causa e efeito. Representam métodos que encontram bastante utilização para a valoração do consumo de capital natural, principalmente quando se objetiva a contabilidade de estoques de recursos naturais e sua dedução da contabilidade de renda (nacional ou regional) [4].

Os métodos indiretos são aplicados quando um impacto ambiental, um determinado elemento do ecossistema, ou mesmo todo um ecossistema não pode ser valorado, mesmo que indiretamente, pelo comportamento do mercado. Assim, estes métodos repousam sobre a utilização de um mercado de substituição definido pela análise dos comportamentos reais. Apesar da aplicabilidade dos métodos depender de variáveis definidas caso a caso, observam-se esforços no sentido de definir situações onde a utilização de um método é apropriada [4].

\section{MATERIAL E MÉTODO}

Serão apresentados neste tópico a metodologia utilizada como critério de pesquisa na elaboração deste artigo. Serão tratadas a classificação da pesquisa, sua natureza, seu universo e amostra, além dos instrumentos de pesquisa utilizados, bem como a análise dos resultados obtidos. O formato será através de um texto corrido, sem sub-tópicos.

Concordando com a taxionomia de [13], a presente pesquisa está classificada nos aspectos que se seguem: quanto aos fins é descritiva, pois está fundamentada na motivação decorrente da necessidade de resolução de problemas concretos detectados por força da análise dos dados coletados na pesquisa, com finalidade prática.

No que se refere aos meios de desenvolvimento desta pesquisa, optou-se pela abordagem bibliográfica, pelo estudo sistematizado, baseado principalmente em consultas e publicações de livros, artigos e redes eletrônicas, as quais, cientificamente acessíveis ao público em geral.

A análise de dados deu-se a partir do conteúdo coletado, fazendo-se a inter-relação entre os aspectos divergentes e convergentes dos resultados. [14] considera que a técnica de análise de dados aplica-se à análise de textos escritos, ou qualquer outro tipo de comunicação, reduzida a um texto ou um documento. Ainda cita que "o objetivo da análise de conteúdo é compreender criticamente o sentido das comunicações, seu conteúdo latente ou manifesto às significações explícitas ou ocultas" [14].

Promulgadas após submetidas e aprovadas pelo Congresso Nacional.

Além disso, há a legislação acidentaria pertinente à área da Previdência Social. Onde se estabelecem os critérios das aposentadorias especiais, do seguro de acidente do trabalho, indenizações e reparações.

Completando essa extensa legislação, devemos lembrar que a ocorrência dos acidentes (lesões imediatas ou doenças do trabalho) pode dar origem a ações civis e penais, concorrendo com as ações trabalhistas e previdenciárias.

\section{RESULTADOS E DISCUSSÕES}

A questão ambiental tem merecido grande destaque no contexto internacional, em virtude da constatação do desenvolvimento econômico e social, imprescindível à civilização moderna, e a desenfreada e em alguns casos, irreversível, degradação dos recursos naturais, gerando a perda da qualidade de vida e pondo em risco a própria sobrevivência humana.

A responsabilidade ambiental pode ser definida como a responsabilidade pelo cumprimento do direito e das normas ambientais, bem como seguir as melhores práticas de preservação ao meio ambiente. Esse conceito passa pela preocupação com o aquecimento do planeta, com os produtos químicos usados na fabricação e com o compromisso de desenvolver produtos que sejam recicláveis.

A responsabilidade ambiental, também é uma questão de cunho pessoal e inerente a todos, pois a soma das ações individuais é o que gera uma sociedade e se cada um estiver atento à parcela de responsabilidade ambiental, então pode-se efetivamente fazer uma grande diferença ao preservar o meio ambiente. 
Qualquer mudança no meio ambiente quer seja desfavorável ou benéfica, total ou parcialmente resultante das atividades, produtos e serviços de uma organização, causa um impacto ambiental.

Na economia globalizada e altamente competitiva da atualidade, torna-se imperativa a necessidade de inovar, levando em consideração os aspectos ambientais.

A implementação de um sistema de Gestão Ambiental de uma empresa pode ser vista como uma inovação, uma vez que trata de um processo que exige uma mudança comportamental e organizacional.

O desafio para garantir o sucesso de um Sistema de Gestão Ambiental é, justamente o de adequá-lo às características e cultural da empresa, levando em consideração os objetivos almejados com a mudança pretendida.

O sucesso da implementação de um Sistema Gestão Ambiental estará, portanto, relacionado a uma série de fatores de ordem estratégica e operacional, voltados à obtenção de ganhos ambientais, sociais e econômicos, bem como a garantia de sobrevivência da organização em um cenário em constante alteração.

Segundo a [15], um sistema de gestão ambiental pode ser definido como um conjunto de procedimentos para gerir ou administrar uma empresa, de forma a obter $\mathrm{o}$ melhor relacionamento com o meio ambiente. O modelo de gestão ambiental deve estabelecer os elos entre a missão da empresa e o efetivo atendimento das expectativas dos clientes.

O modelo de gestão ambiental incorpora em seus princípios de qualidade os requisitos determinados pelas normas NBR serie ISO 14000 instituídas pela Associação Brasileira de Normas Técnicas (1996). Tais instrumentos legais se baseiam em normas internacionais de gestão ambiental que têm por objetivo prover as organizações com elementos de um sistema ambiental eficaz, passível de integração com outros requisitos de gestão, de forma a auxiliá-las a alcançar seus objetivos ambientais e econômicos. As normas da série ISO 14000 que tratam dos sistemas de gestão ambiental compartilham dos princípios comuns estabelecidos para sistema da qualidade da série de Normas NBR ISO9000. Enquanto os sistemas de gestão da qualidade tratam das necessidades dos clientes, os sistemas de gestão ambiental atendem às necessidades de um vasto conjunto de partes interessada (órgãos públicos, sindicato, ONG's, empregados, acionistas, etc.) e às crescentes necessidades da sociedade sobre proteção ambiental.

Para a [15], o Sistema de Gestão Ambiental deve ser entendido como um conjunto de decisões assumidas a fim de obter um equilíbrio dinâmico entre missão, objetivos, meios e atividades. Uma das normas da ISO Série 14000, ou seja, a ISO 14000 estabelece as especificações e os elementos de como se deve implementar um sistema de gestão ambiental.

A responsabilidade social hoje é uma preocupação de todos, onde as empresas que são certificadas enfatizam que é de extrema importância a questão dentro da sua organização. De acordo com autores estudados neste trabalho, as empresas através da responsabilidade social e desenvolvimento sustentável, devolvem para a sociedade o que tiram dela através de benfeitorias para a comunidade, além de utilizar seu "poder de marketing", para motivar a sociedade a se engajar em projetos deste tipo ou simplesmente ser mais consciente no que fazer, como usar, e como preservar.

Através de projetos de responsabilidade social, as empresas conquistam parceiros internos e externos, sendo auxiliar as empresas a produzir sem agredir ao meio ambiente, com redução de custos e despesas através das reciclagens, e fornecimento de conhecimento em gerenciamento ambiental para outras organizações e inovando em seus processos sem que haja desperdício nem gerando resíduo, aderindo assim a Produção Mais Limpa integrando os objetivos ambientais aos processos de produção de produção,reduzindo assim os resíduos e as emissões em termos de quantidade de periculosidade.

A gestão ambiental sob a ótica das organizações, está crescendo a cada dia principalmente por questões comerciais, de consumidores e pela legislação vigente, sendo uma área em evolução dentro e fora das organizações e em pouco tempo a empresa que não possuir um programa de gerenciamento ambiental estará fadada ao fracasso.

\section{CONCLUSÃO}

$\mathrm{Na}$ visão tradicional da empresa como instituição apenas econômica, sua responsabilidade consubstancia-se na busca da maximização dos lucros e na minimização dos custos além disso. No Brasil, a gestão do meio ambiente caracteriza-se pela desarticulação dos diferentes organismos envolvidos, pela falta de coordenação e pela escassez de recursos financeiros e humanos para gerenciamento das questões relativas ao meio ambiente. $\mathrm{O}$ desafio de proteger o meio ambiente é fazer com que a consciência ecológica nas organizações, seja pleno e aceito como uma oportunidade de se atingir novos níveis de desempenhos lucrativos.

O presente estudo passou por um levantamento bibliográfico sobre o tema, que descreveu, sobre a gestão ambiental e suas contribuições para as organizações na atualidades inserindo assim a Produção Mais Limpa (PML) um programa que está ligado há um modelo de gestão simples e na melhoria contínua, adotando novas formas de produção que reduzem o uso de recursos naturais. Percebe-se que a empresa pretende trabalhar dentro de um conceito de Produção Mais Limpa, ou seja, que quer produzir mais e melhor com menos recursos, deve considerar Sistema de Gestão Ambiental como um compromisso para proteger o meio ambiente e reduzir a quantidade de poluentes no mesmo. Contudo verificouse que a sociedade preocupa-se cada vez mais com o meio ambiente e está se conscientizando de que a variável ambiental é importante e envolve a todos. No entanto as organizações estão percebendo, esta preocupação com o meio ambiente que devido à pressão por parte da sociedade, dos governos das instituições financeiras internacionais das organizações não governamentais (ONGs), novos conceitos referentes à Gestão Ambiental e as exigências de produtos que foram elaborados com elevado comprometimento com o meio ambiente estão sendo divulgados.

Desta maneira, entende-se que a implantação da gestão ambiental como parte do gerenciamento é responsável pela identificação, controle, monitoramento e redução dos impactos ambientais. Mas a preocupação com o meio ambiente não parou de crescer e acabaram atingindo o próprio mercado, redesenhando-o com o estabelecimento de um verdadeiro mercado verde, que torna os consumidores tão temíveis quanto os órgãos de meio ambiente. Com isso, a proteção ao meio ambiente deixa de ser uma exigência punida com multas e sanções e inscreve-se em um quadro de ameaças e oportunidades, e a própria permanência ou saída do mercado.

\section{AGRADECIMENTOS}

A Faculdade Venda Nova do Imigrante (FAVENI), pelo apoio à pesquisa. 


\section{REFERÊNCIAS}

[1] Almeida, Fernando. Responsabilidade Social e Meio Ambiente. Rio de Janeiro: Elsevier, 2008.

[2] Andrade, Rui Otávio Bernardes de. Tachizawa, Takeshy. Carvalho, Ana Barreiros.Gestão Ambiental enfoque estratégico aplicado ao desenvolvimento sustentável. $2^{\circ}$ ed. São Paulo: Makron Books,2002.

[3] Barbieri, José Carlos. Gestão Ambiental Empresarial: conceitos, modelos e instrumentos. São Paulo: Saraiva, 2004.

[4] Dias, Reinaldo. Gestão Ambiental: Responsabilidade social e sustentabilidade. São Paulo: Atlas, 2010.

[5] Neiva, Álvaro. Controle dos recursos naturais nas mãos da sociedade civil. Revista Ecologia \& Desenvolvimento. No 11, p. 25. São Paulo - mar. 2005.

[6] Reis, Maurício J. L. ISO 14000: Gerenciamento Ambiental: em novo desafio para a sua competitividade. Rio de Janeiro: Qualitymark, 2006.

[7] Savitz, Andrew W. A Empresa Sustentável: o verdadeiro sucesso é o lucro com responsabilidade social e ambiental. Rio de Janeiro: Elsevier, 2007.

[8] Gusmão, Antônio C. de Freitas de; Martini Júnior, Luiz Carlos de. Gestão Ambiental na Indústria. Rio de Janeiro, 2009.

[9] Santos, R.F. Livro: Planejamento Ambiental: Teoria e Prática. Editora: oficina de Textos. São Paulo, 2004.

[10] Benjamin, Antônio Herman de Vasconcellos e. A natureza no direito brasileiro: coisa, sujeito ou nada disso. Caderno jurídico, Escola Superior do Ministério Público, nº. 2, julho de 2001.

[11] Afonso, Fátima. Natureza e Negócios em Equilíbrio. Revista Planeta.SãoPaulo.Ano 32 n 395 , agosto 2005.p 72-77.

[12] Donaire, Denis. Gestão Ambiental na Empresa. $2^{\circ}$ ed. São Paulo: Atlas, 2008.

[13] Vergara, Sylvia Constant. Projetos e relatórios de pesquisa em administração. 4a . Edição. São Paulo: Atlas, 2010.

[14] Chizzotti, Antônio. Pesquisa em ciências humanas e sociais. 7a. Edição. São Paulo: Cortez, 2008.

[15] ABNT - NBR ISO 14001 - Associação Brasileira De Normas Técnicas: sistemas de gestão ambiental: especificação e diretrizes para uso. Rio de Janeiro, 1996. 